\title{
INTERNATIONAL MIGRATION OF HIGHLY SKILLED WORKERS TO THE EU COUNTRIES
}

\author{
Ani Galstyan \\ Russian-Armenian University, Yerevan, Armenia
}

Maintaining the EU's position in the world is preconditioned (among other things) by sustainable economic growth in its member states. Currently, all the EU countries are facing the effects from the rapidly aging population, which is one of the most serious obstacles to sustainable economic growth. In the short term, it may be possible to eliminate the effects of aging population through better use of available human resources. However, in the longer perspective, this will not be enough to counter unfavorable demographic trends. In this context, it will be necessary to increase the share of the economically active population, and this can be partially done through international migration of highly qualified workers. However, our study shows that the level of immigration of highly qualified workers remains modest in most of the EU countries. In this paper, we are analyzing the causes behind the current situation and are also trying to formulate recommendations for migration policy focused on highly skilled labor. At the same time, we are aware that, while international migration contributes to the accumulation of human capital, it cannot by itself solve the structural issues of European labor markets.

Keywords: labor migration; highly skilled workers; aging population; European Union

\section{Introduction}

As of today, all the EU countries are facing the effects of aging population. In other words, the share of the working-age population (15-64 years) within the European Union has started to decrease (see Fig. 1 which illustrates the rate of people aged 15 to 64 as compared to people aged 65+, EU-28, 2001, 2018 and also forecast for 2080).

The reduction in the share of working-age population could lead to a reduction in economic growth if European countries do not succeed in mobilizing the underutilized labor force as well as in promoting productivity growth.

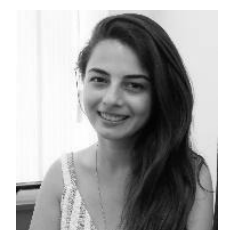

\section{Ani Galstyan}

Postgraduate student, Lecturer at the Department of Economics and Finance, RussianArmenian (Slavonic) University, Yerevan, Armenia.

Research interests: migration, exchange rate regulation, economic growth.

E-mail: ani.galstyan@rau.am 
However, immigration could also be a solution to the problem since most migrants arrive during the most productive years of their lives. This is the case for the EU as a whole, where the net migration rate far exceeds the natural increase in population (OCDE, 2019).

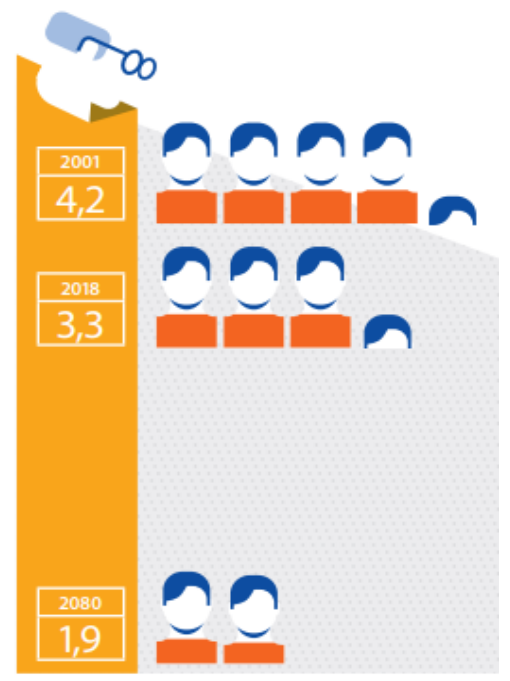

Figure 1 - Aging population in Europe (Source: Eurostat)

However, the shortage of manpower and skills in Europe is not only a consequence of unfavorable demographic development. They are also subject to changes in demand at the local/regional labor markets. Relocation and the growing importance of information economy together are modifying the characteristics of labor market needs and, therefore, of the skills demanded. Given this situation, European countries should endeavor to adjust economic migration trends to the needs of the labor market.

Naturally, international migration of highly skilled workers alone cannot solve all the structural problems of European labor markets. Therefore, it is necessary to carry out multidimensional activities. Today, several EU countries are already using immigration to adjust their labor market. One of their objectives is to attract immigrant workers who have the necessary skills. In this context, we consider it useful to analyze the situation at European labor markets as well as the issues encountered by highly qualified immigrants in the related countries. The results of this analysis could contribute to the development of more effective migration policies, in European and other countries.

\section{Theoretical basis}

As it has been mentioned above, the volume of economically active population in the EU has been decreasing for a while by now. This decrease could lead to a reduction in future GDP. Such negative trends can be reversed through:

- mobilization of unused labor resources,

- growth in labor productivity,

- immigration of skilled workforce.

However, the ability of migrants to mitigate the impact of demographic aging in Europe depends on the capacity of the host countries to ensure the consistency between the 


\section{INTERNATIONAL MIGRATION OF HIGHLY}

skills of migrants and the needs of the local labor markets. What is the current and future situation in Europe in this regard?

Naturally, it is impossible to accurately predict the future development of labor markets, because such phenomena as globalization, technological progress, and changes in the organization of work will have significant impacts on future labor market trends. New sectors are likely to emerge due to the gradual shift towards low-carbon sustainable economies and different socioeconomic realities, while many traditional occupations and sectors will be replaced or become obsolete (Cedefop, 2013a). There is no doubt that imbalances between supply and demand at the labor market as well as in skills' levels will always predominate to a considerable degree in economies (Sattinger, 2013). Certain structural trends that have hit European labor markets (notably the evolution towards a service economy, the aging of active population, and the raising levels of public education) will persist (Cedefop, 2013b).

Cedefop, which forecasts the supply and demand of skills at European labor markets, takes these facts into account. Its macroeconomic model assumes that the proportion of highly skilled jobs in the next 10 years will increase. The results of this model are summarized in Tab. 1.

Table 1 - Projection of the key indicators of the labor market situation for the working-age population (20-64 y.o.) in the EU-28, 2012-2025 (all in \%)

(Source: Cedefop, https://www.cedefop.europa.eu/)

\begin{tabular}{|l|c|c|c|}
\hline & 2012 & 2020 & 2025 \\
\hline Activity rate & 76.0 & 77.6 & 78.4 \\
\hline Employment rate & 68.5 & 69.6 & 71.2 \\
\hline Unemployment rate & 10.2 & 10.3 & 9.1 \\
\hline Inactivity rate & 24.0 & 22.4 & 21.6 \\
\hline
\end{tabular}

Cedefop based its model on the fact that demand for highly skilled workers has increased steadily in the recent decades. At the same time, low-skilled trades have grown while medium-skilled professions have declined. This polarization of jobs is observed in several OECD countries. Acemoglu \& Autor (2010) depicted the simultaneous expansion of the share of high-skill \& high-wage jobs as well as low-skill, low-wage occupations in both United States and the EU.

Several factors could explain the polarization of jobs. Autor et al. (2013) put forward a hypothesis based on routinization: some moderately skilled jobs are disappearing due to technological advances, and relative demand is increasing for the jobs with non-routine tasks. The latter are not only abstract tasks requiring higher level of education, but also nonrepetitive manual tasks, which characterize many professions in the service sector, for example, caring of the elderly, etc.

Other factors could be partly responsible for the drop in the number of jobs in certain trades, including rapid development of offshoring and subcontracting to the countries in other parts of the world (Goos et al., 2014).

Michaels et al. (2014) have shown that polarization of jobs results mainly from the advance of information and communication technologies. This increases the relative demand for highly qualified workers and reduces the needs for intermediary workers. 
Another fact to take into account in the analysis of the labor markets is that between 2000 and 2010, the level of education of new entrants to the labor market was much higher than that of the workers retiring at the same time. For every worker with a good level of education who has retired in Europe, almost three new ones have entered the labor market. Exactly the opposite has occurred for the people with lower levels of education.

However, growth in the share of highly skilled workers is expected to slow in the future, mainly because the number of highly skilled workers who retire will increase significantly. This phenomenon did not exist in the 2000-2010 period. In this regard policy makers in the UK and the EU should pay attention to better recognition of the qualifications of migrant workforce, making it a priority area (Př́ivara et al., 2019). Moreover, atrracting highly skilled migrant workers to host countries requires a more favourable approach based on integrative efforts of a large body of institutions as well as assessment of cultural climate and quality of migration services (Př́ivara \& Rievajová, 2019).

Although the growth of highly educated labor force should remain positive in most countries, it will be lower than it was observed during 2000-2010. This slowdown could lead to skills shortages in the context of persistent demand and therefore could lead to increased competition for attracting new talents to the EU countries.

\section{The status of immigrants at European labor markets}

Often highly skilled immigrants take up the jobs for which they are overqualified. Thus, it is very important to identify the factors which are at the origin of such a situation, to develop migration policies that would be able to resolve this situation.

In this context, we should highlight that the status of immigrants seems to vary depending on a particular labor market of the destination countries. Only in Ireland and the UK do immigrants from the EU accept more low-skilled jobs than the immigrants from outside the EU. This situation is a consequence of intensive immigration to these two countries after the enlargement of the EU in 2004. The enlargement of the EU has led to a significant increase in the intra-European travel, mainly of the young workers from the new member states seeking better salaries in the EU-15 countries. Part of this movement involves medium and highly skilled workers, who often accept lower-level jobs.

The situation in the southern European countries is of interest too. Education levels in these countries have evolved faster than the nature of jobs. Low-skilled jobs are plentiful but cannot find takers, thus attracting many immigrants, while highly skilled jobs are widely covered and attract only a few foreign applicants.

The situation is different in the Central European countries, where wages are relatively low as compared to the rest of the EU. Immigrants, who are only present in very small numbers, are probably highly qualified workers from other EU countries or people sent by their parent company to set up subsidiaries.

The state with which we are confronted in the countries of the North, and also in Belgium, the Netherlands, in France and Austria, as well as in Czech Republic, is that in case of the jobs requiring high qualification, the share of immigrants from within EU is smaller than that of the natives newly arrived at the labor market but higher than that of the immigrants outside the EU. Non-equivalent or unrecognized degrees may be among the possible reasons behind this situation. 


\section{INTERNATIONAL MIGRATION OF HIGHLY}

Studies on the international migration of highly skilled workers attempt to explain why immigrants are more affected by downgrading rather than by competition with the local residents. Most of this work is based on a theoretical framework related to human capital.

The main reason for downgrading is that the returns to education and work experience of immigrants are lower than those of the natives. This fact is generally associated with the inability to transfer skills perfectly between the country of origin and the host country.

These difficulties may be linked to the non-recognition of foreign diplomas by many host countries. However, they can also be the result of the fact that certain diplomas are specific to a country of origin, and that the knowledge acquired in this country is almost useless in a host country. This is, for example, the case with diplomas from the Faculty of Law. Another possible explanation for the low returns to training acquired abroad is the lack of skills in the language of a host country.

Among the empirical research that has examined the impact of language in various host countries, one can mention the study of Dustmann and Fabbri (on the United Kingdom), Dustmann, and Van Soest (on Germany) among others. This work concluded that the immigrants having a better command of the host country language are generating higher incomes and have higher employment rates as compared to the immigrants who do not speak the language of a host country.

As mentioned above, the theoretical approaches that explain the differences in skill returns of immigrants and natives are based on the theory of human capital. In this theoretical framework, labor markets are competitive and wages equal the productivity of the workforce. Unfortunately, they ignore the non-competitive models where employers also play an important role at the job market.

Recent publications have made progress in this context. These publications explore why employers prefer to employ local people. The main reason, according to them, is massscale non-recognition of immigrants' qualifications. Nordin shows that immigrants with diplomas acquired in a country other than Sweden are less likely to find a job in this country (Nordin, 2017).

Dumont and Monso show that immigrants who studied abroad have higher rates of downgrading (Dumont \& Monso, 2017). Nielsen also shows in the case of Denmark the prevalence of downgrading immigrants is lower if the diploma was obtained in a host country (Nielsen, 2011).

Finally, employers favor domestic workers because recruiting from abroad is generally more expensive than domestic recruiting, except the case of multinational companies that can transfer skilled workers from a subsidiary located in another country.

\section{Recommendations for better management of highly skilled worker migration}

Several EU countries, where labor shortages are expected in the short or medium term, are already using immigration as a means of adjusting their labor markets. One of their main objectives is to select and attract immigrant workers with the necessary skills. A better understanding of the obstacles which prevent immigrants from making full use of their qualifications at the local labor markets could facilitate the development of more targeted policies on the migration of highly qualified workers.

The experience of many EU countries shows that immigration policies that select migrants only based on their level of education do not allow the most competent people to be 
identified and attracted. This is mainly caused by the fact that the level of education is only a partial indicator of the qualification level. However, there is no simple method to take into account the differences in the levels of educational programs in different countries. Furthermore, formal education levels are not a direct indicator of skills. Indeed, workers with the same educational backgrounds may have different skill levels (OECD, 2019).

Skills are acquired not only through the formal education system, but also while practicing. Selective migration policies should, therefore, take into account other, additional factors, such as language skills or having specific professional skills tested before leaving the country of origin.

The examples of good cases include the experience of the Netherlands or Germany. The Netherlands seeks to attract graduates from prestigious universities through the Regeling Hoogopgeleiden scheme, while Germany is increasingly seeking to validate the skills of migrants before welcoming them, for example, linguistic skills or having specific professional skills tested before leaving the country of origin.

Selective migration policies of European countries must also tackle another problem: these countries prefer to leave the recruitment of immigrants from third countries to the initiative of employers themselves. The advantage of this approach is that immigrants have a job upon arrival. However, this requires that employers actually take the initiative to recruit workers.

Employers will recruit from abroad if they want to increase the volume of production but they cannot find suitable personnel at the domestic labor market. In this context, we should highlight that recruiting from abroad is not the only option available to employers in such a situation. They can also increase the number of working hours of the existing employees, implement new technical solutions, relocate or retrain employees. The option of recruiting from abroad mainly assumes that employers have the necessary contacts, means, and knowledge to recruit from another country. Currently, most companies have little experience in recruiting overseas and thus may need public assistance to meet their labor needs.

\section{Conclusion}

In the context of knowledge-based economies with quickly aging populations, as is the case in most of the EU countries, attracting highly qualified immigrants to guarantee sustainable economic growth and national competitiveness is a top priority. We must emphasize, however, that the EU countries have so far been unable to attract a sufficient number of highly skilled workers from third countries, despite the adoption of certain selective migration policy measures (under the Blue Card initiative). Besides, many of the skilled immigrants are immediately downgraded at the European labor markets. We believe that better understanding of the difficulties encountered by immigrants at the European labor markets may help to solve this and other related issues.

At the same time, however, it is clear that, while international migration of highly skilled workers promotes the accumulation of human capital in the EU countries, it cannot by itself solve the structural problems of European labor markets. Changes at any labor market happen faster than demographic changes in the same country. Immigrants will often be called upon not to replace the retiring baby boomers, but rather to meet the labor and skill needs of a rapidly changing labor market. 


\section{INTERNATIONAL MIGRATION OF HIGHLY}

\section{Acknowledgment}

This work was supported by the Russian-Armenian University within the framework of the grant of the Ministry of Education and Science of the Russian Federation.

\section{References:}

Acemoglu, D. \& Autor, D. (2010). Skills, Tasks and Technologies: Implications for Employment and Earnings. Handbook of Labor Economics, 4.

Autor, D., Levy, F. \& Murnane, R. J. (2013). The Skill Content Of Recent Technological Change: An Empirical Exploration. Quarterly Journal of Economics, 118.

Cedefop (2013a). Skills for a Low Carbon Economy: The Role of VET in a Sustainable Energy Scenario. Cedefop Research Paper, 34.

Cedefop (2013b). Future Skill Supply and Demand in Europe: Forecast 2012. Cedefop Research Paper, 26.

Dumont, J.C. \& Monso, O. (2017). Adéquation entre formation et emploi: un défi pour les immigrés et les pays d'accueil. Perspectives des migrations internationales 2017, OCDE, Paris.

Goos, M., Manning, A. \& Salomons, A. (2014). Explaining Job Polarization: Routine - Biased Technological Change and Offshoring. American Economic Review, 104(8), 2509-2526.

Michaels, G., Natraj, A. \& Van Reenen, J. (2014). Has ICT polarized skill demand? Evidence from eleven countries over 25 years. Review of Economics and Statistics. 96(1), 60-77.

Nielsen, C.P. (2011). Immigrant Over-education: Evidence from Denmark. Journal of Population Economics, 24, 499-520.

Nordin, M. (2017). Immigrants Returns to Schooling in Sweden. IFAU, Working Paper, 12, IFAU.

Přívara, A., Rievajová, E. \& Yüceşahin, M. (2019). Labour Market Disadvantages Faced by Migrant Workers from Czech Republic, Hungary, and Slovakia in Britain. Migration Letters, 16(4), 585-594.

Př́ivara, A. \& Rievajová, E. (2019). Destination Marketing and Policies Attracting High-Skilled Individuals in Germany and Singapore. Transitional marketing journal, 7(2), 229-244.

OCDE (2019). Perspectives des migrations internationales de 1'OCDE 2019. Éditions OCDE, Paris.

Sattinger, M. (2013). Qualitative Mismatches. Foundation and Trends in Microeconomics, 8(1-2), 1168.

Paper submitted

Paper accepted for publishing

Paper published online
12 April 2020

16 June 2020

31 July 2020 